\title{
Korean Language Phonological Interference to Indonesian Language and Implication in BIPA
}

\author{
Liliana Muliastuti ${ }^{1}$, Aulia Nurnovika ${ }^{2}$, and N. Lia Marliana ${ }^{3}$ \\ ${ }^{123}$ State University of Jakarta, Indonesia, \\ ${ }^{1}$ liliana.muliastuti@unj.ac.id; 2aulianurnovika@gmail.com; \\ nliamarliana@unj.ac.id
}

\begin{abstract}
This study obtained information about Korean language phonological interference with Indonesian language. The object of research is phonological interference taken from Korean speech in a YouTube video. The focus of this research is in the field of phonology. The research method uses descriptive qualitative methods with content analysis techniques. Data was obtained from youtube videos of 21 Koreans around 40 videos when they speak in Indonesian language. The results of this study include the appearance of phonemes $/ 1 /$ and $/ \mathrm{a} /$, phoneme permeation $/ \mathrm{h} /$ and $/ \mathrm{r} /$, phoneme changes $/ \mathrm{r} /$ to $/ \mathrm{l} /$ and vice versa, phoneme changes $/ \mathrm{f} /$ and $/ \mathrm{v} /$ to $/ \mathrm{b} /$, $/ \mathrm{p} /$, and $/ \mathrm{ph} /$, phoneme changes $/ \mathrm{p} /$ becomes $/ \mathrm{b} /$ and vice versa, phoneme changes /c/ becomes $/ \mathrm{j} /$, phoneme changes $/ \mathrm{k} /$ becomes $/ \mathrm{g} /$, phoneme changes $/ \mathrm{k} /$ becomes $/ \mathrm{y} /$, and phoneme changes $/ \mathrm{p} /$ to $/ \mathrm{m} /$. The highest interference result is 92 phonemes $/ 1 /$ appearing in the middle of words $(48,2 \%)$. The lowest interference results from a phoneme change $/ \mathrm{p} /$ to $/ 1 /$ in 1 word. Several factors cause Korean interface to Indonesian, namely vowel rules that must accompany foreign consonants, the absence of consonants in Korean, consonant assimilation rules, and the relationship of two consonant sounds that can be used with the same letter in Korean. The most common factor in Korean language that opposes the pronunciation of Indonesian language Korean people is consonant. The results of this study can be used in fostering, learning, and developing Indonesian language education for foreign speakers (BIPA).
\end{abstract}

Keywords: Phonological Interference, Indonesian Language, Korean Language

\section{PENDAHULUAN}

Pada tahun 2013, total mahasiswa asing yang mengikuti Program Darmasiswa RI — suatu program beasiswa bagi mahasiswa asing yang ingin belajar bahasa dan budaya Indonesiasejak 1974 berjumlah 4.563 orang dari 97 negara [1]. Angka tersebut menunjukkan tingginya minat orang asing belajar bahasa Indonesia. Secara khusus, minat orang Korea terhadap bahasa Indonesia cukup tinggi. Namun, besarnya minat orang Korea belajar bahasa Indonesia ini tidak selalu seimbang dengan sarana pengaplikasian bahasa itu sendiri. Orang Korea yang tinggal dan belajar di Indonesia tentu akan lebih mudah mengaplikasikan bahasa Indonesia yang dipelajarinya. Mereka dapat berkomunikasi langsung dengan warga sekitar. Sementara itu, orang Korea yang belajar bahasa Indonesia di negaranya dapat berkomunikasi dengan sesama teman dan guru saja. Oleh karena itu, beberapa di antara mereka akhirnya menggunakan 
YouTube sebagai sarana berbahasa Indonesia dan berkomunikasi langsung dengan pengguna atau penonton YouTube dari Indonesia. Video-video di YouTube tersebut berisi beragam konten, contohnya mengenalkan budaya Korea dan Indonesia. Beberapa youtuber membuat video utuh berbahasa Indonesia dan lainnya berganti-ganti antara bahasa Korea dan bahasa Indonesia. Namun, tetap saja ditemukan kesalahan berbahasa Indonesia yang dilakukan dan terlihat pada terjemahan teks bahasa Indonesia dan pelafalan yang kurang tepat ketika berbicara, misalnya kesalahan pelafalan bunyi /l/ dan /r/. Hal ini terjadi akibat representasi fonologi seseorang telah gagal. Menurut Sinha, dkk, penguasaan representasi fonologis yang berhasil membutuhkan persepsi fonemik yang akurat [2]. Kesalahan berbahasa yang dilakukan pembelajar sebagai hasil penggunaan unsur bahasa pertama ketika berbicara/menulis dalam bahasa kedua disebut sebagai interferensi [3]. Interferensi menurut Weinreich sebagai perubahan sistem suatu bahasa karena adanya persentuhan bahasa tersebut dengan unsur-unsur bahasa lain oleh penutur bilingual yang menggunakan dua bahasa secara bergantian [4]. Interferensi berarti adanya saling pengaruh antarbahasa; dalam bentuk yang paling sederhana berupa pengambilan satu unsur dari satu bahasa dan digunakan dalam hubungannya dengan bahasa lain. Hampir senada, Lado dan Sunyono menyatakan, pengaruh antarbahasa itu dapat juga pengaruh kebiasaan dari bahasa pertama (ibu) yang sudah dikuasai penutur ke dalam bahasa kedua [5]. Ketika belajar bahasa kedua pasti akan terjadi interferensi, terlebih lagi bila kedua bahasa memiliki perbedaan yang sangat signifikan. Menurut Berthold (dalam Archvadze) interferensi dapat dilihat sebagai perpindahan elemen dari satu bahasa ke dalam bahasa lainnya pada berbagai level, yakni fonologi, gramatikal, leksikal, dan ortografi [6].

Interferensi fonologis terjadi apabila penutur mengungkapkan kata-kata suatu bahasa dengan menyisipkan bunyi-bunyi bahasa dari bahasa lain. Pemelajar bahasa memiliki struktur psikologi tersembunyi di dalam otaknya yang secara otomatis aktif, jadi pelafalan bahasa pertama sering terbawa ke bahasa kedua ketika penutur atau pemelajar menggunakan bahasa keduanya [7]. Interferensi fonologis dipengaruhi proses perubahan bunyi yang terjadi saat membentuk bunyibunyi bahasa. Hal ini karena, pembentukan bunyi bahasa kedua mungkin saja terpengaruh oleh kaidah bunyi bahasa yang dimiliki bahasa asli [4]. Interferensi fonologi lahir dari adanya perubahan fonologi akibat pengaruh dari bunyi bahasa Korea terhadap bahasa Indonesia. Perubahan fonologi disebut juga proses fonologis atau proses morfofonemik, morfonemik, morfofonologi, atau morfonologi. Proses fonologis dalam bahasa Indonesia dapat berwujud: (1) asimilasi, (2) netralisasi, (3) diftongisasi, (4) monoftongisasi, (5) epentesis dan metatesis, (6) pemunculan fonem, (7) pelesapan fonem, (8) peluluhan fonem, (9) perubahan fonem, dan (10) pergeseran fonem.[8] Sementara itu, bahasa Korea juga memiliki aturan perubahan bunyinya sendiri. Antara lain, (1) harmonisasi vokal, (2) kontraksi dan pelepasan vokal, (3) asimilasi konsonan, (4) tensifikasi (penekanan), (5) aspirasi (letupan), dan (6) palatalisasi [9]. Bunyi vokal dan konsonan, serta aturan perubahan bunyi yang berbeda antara bahasa Korea dan bahasa Indonesia ini dapat menjadi dasar terjadinya interferensi fonologis. Contohnya, siswa Korea Selatan tidak dapat membunyikan [r].[1] Menurut Park KyeongJae[10], kesalahan pelafalan yang paling sering dilakukan orang Korea saat berbicara bahasa Indonesia yakni bunyi [r], [1], [f], [v], dan [z]. Orang Korea tidak dapat membunyikan huruf-huruf tersebut karena di dalam bahasa Korea atau khususnya bidang fonologi tidak terdapat bunyi yang sama. Ia juga menambahkan bahwa latihan dan pengulangan dapat meningkatkan kemampuan pelafalan. Dapat ditemukan pula contoh pada penelitian pendahulu perangkapan bunyi /1/, aspirasi bunyi [la.ci] menjadi [la.chi], perubahan bunyi [ga.un] menjadi [ka.wun], pelesapan bunyi [gi.tar], menjadi [gi.ta], serta penambahan bunyi /ə/ dan /i/. [11] 


\section{METODE PENELITIAN}

Penelitian ini merupakan penelitian kualitatif dengan teknik analisis isi. Subjek penelitian ini adalah 21 orang Korea yang berakun YouTube berbahasa dan berkonten Indonesia. Setelah mengobservasi 21 orang tersebut, diunduhlah 40 video. Setiap orang 1-3 video berdurasi 3-20 menit secara acak. Setelah video dikumpulkan, dilakukan pengisian kartu data, pentranskripsian, dan pemisahan data interferensi fonologisnya. Lalu dilakukan pengisian kartu analisis. Bagian faktor penyebab dari bahasa Korea, terdiri atas vokal, konsonan, dan aturan perubahan bunyi berupa harmonisasi vokal, asimilasi konsonan, kontraksi, dan pelepasan vokal, tensifikasi, aspirat, dan palatalisasi. Bagian penyimpangan dalam bahasa Indonesia, terdiri atas asimilasi, netralisasi, diftongisasi, monoftongisasi, epentesis dan metatesis, pemunculan fonem, pelesapan fonem, peluluhan fonem, perubahan fonem, dan pergeseran fonem. Setelah itu, hasil analisis dideskripsikan, diinterpretasi, dan dibahas kembali hubungannya dengan teori. Terakhir, dideskripsikan pula implikasi hasil penelitian ini terhadap pelatihan, pengajaran, dan pengembangan BIPA, khususnya bagi penutur Korea.

\section{HASIL DAN PEMBAHASAN}

Bentuk interferensi fonologis bahasa Korea terhadap bahasa Indonesia dalam penelitian ini dibagi menjadi pemunculan fonem, perubahan fonem, dan pelesapan fonem. Hasil interferensi tertinggi ditemukan pada pemunculan fonem sebanyak 107 kata $(56,1 \%)$. Selanjutnya disusul perubahan fonem sebanyak 53 kata $(27,7 \%)$, kemudian pelesapan fonem sebanyak 31 kata (16,2\%). Pada fenomena pemunculan fonem, muncul bunyi /1/ dan /ə/. Fonem /1/ sebanyak 92 kata (48,2\%). Hal ini disebabkan oleh munculnya fonem /1/ untuk mendampingi fonem /1/ yang terdapat di tengah kata namun di awal silabel. Misalnya, kata pada kata [sə.bəl.lum] yang seharusnya dibaca [sə.bə.lum]. Fonem /ə/ sebanyak 15 kata (7,9\%). Fonem ini berperan sebagai pendamping fonem konsonan yang sulit dibunyikan oleh orang Korea. Misalnya, pada kata [maafə] yang seharusnya dibunyikan [maaf]. Pada fenomena pelesapan fonem, bunyi yang lesap yakni $/ \mathrm{h} / \mathrm{dan} / \mathrm{r} /$. Keduanya terjadi akibat ketiadaan bunyi tersebut di akhir silabel dalam bahasa Korea. Fonem $/ \mathrm{h} /$ yang lesap sebanyak 29 kata (15,2\%). Misalnya, pada kata [muda] yang seharusnya dibaca [mudah]. Fonem /r/ yang lesap sebanyak 2 kata (1\%). Misalnya pada kata [kaba] yang seharusnya dibaca [kabar].

Pada fenomena perubahan fonem, rata-rata perubahan bunyi yang terjadi akibat dua bunyi yang saling bertukar karena lambang bunyi atau hurufnya sama. Perubahan bunyi /r/ menjadi /1/ sebanyak 24 kata (12,6\%). Misalnya, pada kata [rabu] menjadi [labu]. Perubahan bunyi /1/ menjadi /r/ sebanyak 6 kata atau 3,2\%. Huruf ( $ᄅ$ ) dalam bahasa Korea memiliki dua bunyi yaitu /r/ dan /1/ sehingga interferensi saling menggantikan ini terjadi. Misalnya pada kata [lupa] menjadi [rupa]. Perubahan bunyi $/ \mathrm{f} / \mathrm{menjadi} / \mathrm{p}^{\mathrm{h}} / \mathrm{sebanyak} 6 \mathrm{kata}(3,2 \%)$. Misalnya, pada kata [maaf] menjadi [maap ${ }^{\mathrm{h}}$. Perubahan bunyi $/ \mathrm{v} /$ menjadi $/ \mathrm{p}^{\mathrm{h}} / \mathrm{sebanyak} 3 \mathrm{kata}(1,6 \%)$. Misalnya, pada kata [video] menjadi [ $\mathrm{p}^{\mathrm{h}}$ ideo]. Perubahan fonem /v/ menjadi /b/ sebanyak 4 kata $(2,1 \%)$. Misalnya, pada kata [levəl] menjadi [lebəl]. Perubahan fonem $/ \mathrm{v} /$ menjadi /p/ sebanyak 2 kata (1\%). Misalnya, pada kata [univərsitas] menjadi [unipərsitas]. Bahasa Korea tidak memiliki bunyi /f/ maupun /v/ sehingga bunyi-bunyi tersebut sering digantikan dengan huruf $(\forall)$ berbunyi /b/ dan /p/ serta huruf (프) berbunyi /ph/.

Perubahan fonem $/ \mathrm{p} /$ menjadi $/ \mathrm{b} /$ sebanyak 2 kata (1\%). Misalnya pada kata [pərtama] menjadi [bərtama]. Perubahan fonem $/ \mathrm{b} /$ menjadi $/ \mathrm{p} /$ sebanyak 1 kata $(0,5 \%)$. Misalnya, pada kata [bantu] menjadi [pantu]. Huruf $(\forall)$ dalam bahasa Korea memiliki dua bunyi yaitu /b/ dan 
$/ \mathrm{p} /$, oleh karena itu interferensi saling menggantikan ini terjadi. Perubahan fonem $/ \mathrm{k} /$ menjadi /g/ sebanyak 1 kata (0,5\%). Misalnya pada kata [tərkənal] menjadi [tərgənal]. Huruf ( $\forall$ ) dalam bahasa Korea memiliki dua bunyi yaitu /g/ dan /k/, sehingga interferensi saling menggantikan ini terjadi. Apalagi bunyi /g/ umumnya muncul di awal silabel. Perubahan bunyi /c/ menjadi /j/ sebanyak 1 kata (0,5\%). Misalnya pada kata [cara] menjadi [jara]. Hal ini terjadi karena huruf ( $ᄌ$ ) dalam bahasa Korea berbunyi /j/, kadang diganti bunyinya menjadi /c/.

Perubahan fonem $/ \mathrm{k} /$ menjadi / $\mathrm{y} /$ sebanyak 2 kata (1\%). Misalnya pada kata [monikmati] menjadi [məninmati]. Hal ini diakibatkan oleh aturan asimilasi konsonan yang mengharuskan huruf ( $\neg$ ) berbunyi /k/ ketika bertemu dengan huruf ( $\square$ ) berbunyi /m/ atau huruf ( $\llcorner$ ) berbunyi $/ \mathrm{n} /$ berubah bunyinya menjadi /y/. Perubahan fonem $/ \mathrm{p} /$ menjadi $/ \mathrm{m} /$ sebanyak $1 \mathrm{kata}(0,5 \%)$. Misalnya, pada kata [hiduplah] menjadi [hidumlah]. Hal ini diakibatkan oleh aturan asimilasi konsonan yang mengharuskan huruf $(\forall)$ berbunyi /p/ ketika bertemu dengan huruf $(\ulcorner)$ berbunyi /r/ atau /1/ berubah bunyinya menjadi /m/.

Interferensi fonologis dikategorikan juga dalam faktor penyebab terjadinya dari bahasa Korea berupa aturan asimilasi konsonan yang menyebabkan bertambah atau berubahnya bunyi konsonan sebanyak 95 kata atau 49,7\%, vokal yang mendampingi bunyi konsonan dari bahasa asing sebanyak 15 kata atau 7,9\%, ketiadaan konsonan sebanyak 31 kata atau 16,2\%, serta konsonan yang saling bertukar karena dua bunyi yang berbeda dituliskan dalam lambang bunyi atau huruf yang sama sebanyak 50 kata atau $26,2 \%$.

Bentuk implikasi dari penemuan fenomena-fenomena ini dapat berupa pembinaan, pengajaran, dan pengembangan BIPA, khususnya bagi penutur Korea. Pembinaan dilakukan kepada pengajar BIPA yang hendak mengajarkan bahasa Indonesia kepada orang Korea agar membuat metode dan media yang lebih inovatif saat mengajarkan pelafalan bahasa Indonesia dan agar disesuaikan dengan kesulitan yang muncul pada penutur Korea sesuai dengan hasil penelitian ini. Pengembangan BIPA dapat dilakukan saat membuat buku, terutama buku BIPA khusus orang Korea. Dengan demikian, bisa ditambahkan kolom-kolom informasi tentang pelafalan yang benar, atau bunyi bahasa Indonesia dan Korea yang jauh berbeda sehingga membutuhkan latihan terus-menerus.

Pengajaran yang dilakukan khususnya untuk memenuhi unit Kompetensi 6 "mengusai penggunaan kosakata dan tata bahasa dalam berbagai jenis teks yang diajarkan," khususnya elemen Kompetensi 6.1 "menguasai pengetahuan tentang penggunaan bunyi bahasa dan pelafalan," dari Permendikbud Nomor 27 Tahun 2017, misalnya dengan menggunakan tongue twister flashcard. Contoh kalimat yang dapat digunakan pada tongue twister flashcard tersebut antara lain, 'keledai makan kedelai di kedai', 'ular melingkar di atas pagar', 'masak mudah makan nikmat', dan sebagainya. Seperti halnya yang dikatakan Park KyeongJae bahwa latihan yang berterusan dapat meningkatkan kemampuan penutur dalam melafalkan bahasa Indonesia dengan baik, terutama pada bunyi-bunyi yang sulit seperti /r/ dan /f/.

\section{SIMPULAN}

Interferensi fonologis dari bahasa Korea terhadap bahasa Indonesia pada orang Korea ditemukan sebanyak 191 kata. Dikategorikan dalam bentuk pemunculan fonem /1/ dan /ə/, pelesapan fonem $/ \mathrm{h} / \mathrm{dan} / \mathrm{r} /$, perubahan fonem $/ \mathrm{r} /$ menjadi $/ \mathrm{l} /$ dan sebaliknya, perubahan fonem /f/ atau /v/ menjadi /b/, /p/, atau / $\mathrm{p}^{\mathrm{h}}$, perubahan fonem $/ \mathrm{b} /$ menjadi $/ \mathrm{p} /$ dan sebalinya, perubahan fonem $/ \mathrm{c} /$ menjadi $/ \mathrm{j} /$, perubahan fonem $/ \mathrm{k} /$ menjadi $/ \mathrm{g} /$, perubahan fonem $/ \mathrm{k} /$ menjadi $/ \mathrm{y} /$, dan perubahan fonem $/ \mathrm{p} /$ menjadi $/ \mathrm{m} /$. Selain itu dikategorikan juga faktor penyebab terjadinya interferensi fonologis ini dari bahasa Korea berupa aturan asimilasi konsonan yang 
menyebabkan bertambah atau berubahnya bunyi konsonan, vokal yang mendampingi bunyi konsonan dari bahasa asing, ketiadaan konsonan, serta konsonan yang saling bertukar karena dua bunyi yang berbeda dituliskan dalam lambang bunyi atau huruf yang sama. Bentuk implikasi dari penemuan fenomena-fenomena ini dapat berupa pembinaan, pengajaran, dan pengembangan BIPA, khususnya bagi penutur Korea. Pembinaan bagi pengajar BIPA yang hendak mengajarkan bahasa Indonesia kepada orang Korea agar membuat metode dan media yang lebih inovatif saat mengajarkan pelafalan bahasa Indonesia. Pengajaran ini untuk memenuhi elemen Kompetensi 6.1 "menguasai pengetahuan tentang penggunaan bunyi bahasa dan pelafalan", dari Permendikbud Nomor 27 Tahun 2017, misalnya dengan menggunakan tongue twister flashcard. Pengembangan BIPA dapat dilakukan saat membuat buku, lalu menambahkan kolom-kolom informasi tentang pelafalan yang benar, atau bunyi bahasa Indonesia dan Korea yang jauh berbeda sehingga membutuhkan latihan terus-menerus.

\section{REFERENCES}

[1] L. Muliastuti, Bahasa Indonesia bagi Penutur Asing, Jakarta: Yayasan Obor Indonesia, 2017.

[2] A. Sinha, A. Sinha, N. Banerjee and R. K. Shastri, "Interference of first language in the acquisition of second language," Journal of Psychology and Counseling, vol. 1, no. 7, pp. 117-122, 2009.

[3] F. Mu'in, "Phonemic Interference of Local Language in Spoken english by Students of English Department of Lambung Mangkurat University," Journal of Language Teaching and Reasearch, vol. 8, no. 1, pp. 64-74, 2017.

[4] A. Chaer and L. Agustina, Sosiolinguistik, Jakarta: Rineka Cipta, 2014.

[5] Aslinda and S. L., Pengantar Sosiolinguistik, Bandung: Refika Aditama, 2014.

[6] E. Archvadze, "The Problems of First Language Interference in the Process of Teaching," in Higher Education - New Technologies and Innovation, Georgia, 2005.

[7] D. H. Utami, B. Wello and H. Atmowardoyo, "The Phonological Interference of Students' First Language in Pronouncing English Sounds (A Case Study on Buginese and Makassarese Students)," ELT Worldwide, vol. 4, no. 2, 2017.

[8] A. Chaer, Linguistik Umum, Jakarta: Rineka Cipta, 2014.

[9] Sekolah Bahasa Korea Universitas Yonsei, Pengucapan Bahasa Korea, Seoul: Penerbit Universitas Yonsei, 1995.

[10] K. Park, "Bahasa Indonesia yang Sering Salah Dilafalkan Orang Korea," in HanIn News, Jakarta, HanIn Publisher, 2018, pp. 53-55.

[11] R. S. Yuniar, "Korean Phonological Interference in Indonesian Language as Second Language," Lantern (Journal on English Language, Culture AND Literature), vol. 2, no. 4, pp. 1-14, 2013.

[12] D. G. Wijaya, "Phonological Interference: A Case Study of Chinese, Japanese, South Korean Students Speaking Indonesian," Skripsi Jurusan Sastra Inggris - Fakultas Sastra UM, 2016. 